\title{
$Q$ fever presenting as recurrent, culture-negative endocarditis with aortic prosthetic valve failure: A case report and review of the literature
}

\author{
Abeer N AlShukairi MD¹, Muhammad G Morshed PhD 2,3 , Neil E Reiner MD FRCPC FACP1,4,5
}

\begin{abstract}
AN AlShukairi, MG Morshed, NE Reiner. Q fever presenting as recurrent, culture-negative endocarditis with aortic prosthetic valve failure: A case report and review of the literature. Can J Infect Dis Med Microbiol 2006;17(6):341-344.
\end{abstract}

The present report describes a case of recurrent, culture-negative endocarditis presenting with aortic prosthetic valve dysfunction in a 62 -year-old man who required four valve replacement surgeries. On each occasion, he presented with valve failure. Fever was only documented during his first presentation. Furthermore, no vegetations were detectable on his aortic valve at transesophageal echocardiography. On the occasion of his most recent presentation, a detailed history of animal exposure - including hunting and skinning deer, moose and other large animals with his bare hands - was the only clue to his diagnosis. Serum antibodies against Coxiella burnetii were strongly positive, and $\mathrm{C}$ burnetii DNA was detected by polymerase chain reaction from his resected aortic valve tissue. Q fever is a worldwide zoonotic infection with diverse reservoirs. This diagnosis should be considered when evaluating unexplained prosthetic valve dysfunction, particularly in the setting of animal exposure.

Key Words: Coxiella burnetii; Endocarditis; Prosthetic valve; $Q$ fever

\section{CASE PRESENTATION}

A 62-year-old man was evaluated for recurrent prosthetic valve dysfunction in the Infectious Diseases Clinic at Vancouver General Hospital (Vancouver, British Columbia) in July 2004. He had his first bioprosthetic aortic valve replacement for presumed rheumatic aortic valve disease in August 1982, and required repair of an aortic paravalvular leak in November 1982. The patient was asymptomatic until June 2001, when he had fever and transthoracic echocardiographic evidence of aortic prosthetic valve regurgitation and no vegetations. He underwent a second bioprosthetic aortic valve replacement. Bacterial, mycobacterial and fungal cultures from the resected valve tissue were negative. Despite this, he received an empirical six-week course of vancomycin and ceftriaxone as recommended for culture-negative endocarditis. For the next 20 months, his condition was stable, until February 2003, when he presented with clinical evidence of congestive heart failure and transthoracic echocardiographic signs of severe aortic regurgitation with paravalvular leak. Again, no vegetations were apparent, and fever was not documented during this episode. This led to a third aortic valve replacement, and on this occasion a metallic St Jude valve was used (23 AGFN-756,

\section{Une fièvre $Q$ se présentant sous forme d'endocardite récurrente négative à la culture accompagnée d'une insuffisance de la prothèse aortique : Un rapport de cas et une analyse bibliographique}

Le présent rapport décrit le cas d'un homme de 62 ans atteint d'une endocardite récurrente négative à la culture accompagnée d'un dysfonctionnement de la prothèse aortique qui a dû subir quatre chirurgies de remplacement valvulaire. À chaque occasion, il présentait une insuffisance valvulaire. On n'a documenté de la fièvre qu'à la première consultation. De plus, à l'échocardiographie transœsophagienne, aucunes végétations n'étaient décelables sur la valvule aortique. Lors de la consultation la plus récente, une anamnèse détaillée de son exposition aux animaux, y compris la chasse et le dépeçage à mains nues de cerfs, d'orignaux et d'autres gros animaux, a procuré le seul indice diagnostique. Les anticorps sériques contre le Coxella burnetti étaient fortement positifs et de l'ADN du C burnetti a été décelé dans des tissus aortiques réséqués par réaction en chaîne de la polymérase. La fièvre $Q$ est une zoonose auprès de divers réservoirs sur la scène mondiale. Ce diagnostic devrait être envisagé lors de l'évaluation d'un dysfonctionnement inexpliqué de la prothèse aortique, notamment en cas d'exposition à des animaux.

${ }^{1}$ Department of Medicine, Faculty of Medicine; ${ }^{2}$ Department of Pathology and Laboratory Medicine, University of British Columbia. ${ }^{3}$ Laboratory

Services, BC Centre for Disease Control; ${ }^{4}$ Department of Microbiology and Immunology, Faculty of Science, University of British Columbia;

${ }^{5}$ Vancouver Coastal Health Research Institute, Vancouver, British Columbia

Correspondence: Dr Neil E Reiner, Division of Infectious Diseases, University of British Columbia, Room 452D, HP/E, 2733 Heather Street,

Vancouver, British Columbia V5Z 3J5. Telephone 604-875-4011, fax 604-875-4013, e-mail ethan@interchange.ubc.ca

Received for publication January 11, 2006. Accepted June 27, 2006 


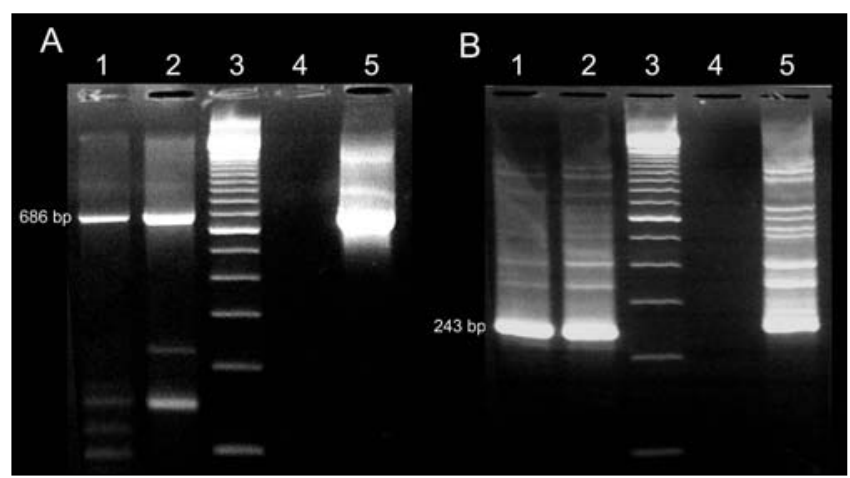

Figure 1) Nested polymerase chain reaction produced a 686 base pair (bp) outer amplicon (A) and a 243 bp inner amplicon (B) using primers based on the Coxiella burnetii transposase gene. Lanes 1 and 2 were loaded with material from resected heart valve tissue; Lane 3-100 bp ladder; Lane 4-negative control; Lane 5 - positive control

hemorrhages, Osler's nodes, Janeway's lesions or splenomegaly. Auscultation of the precordium did not reveal any cardiac murmurs. Chest examination was significant for basal bilateral fine crackles. Laboratory investigations showed a total white blood cell count of $8.3 \times 10^{9}$ (normal range $4 \times 10^{9}$ to $11 \times 10^{9}$ ), hemoglobin level of $124 \mathrm{~g} / \mathrm{L}$ (normal range $135 \mathrm{~g} / \mathrm{L}$ to $175 \mathrm{~g} / \mathrm{L}$ ) and platelet count of $209 \times 10^{9}$ (normal range $125 \times 10^{9}$ to $\left.350 \times 10^{9}\right)$. The erythrocyte sedimentation rate was $32 \mathrm{~mm} / \mathrm{h}$ (normal range $0 \mathrm{~mm} / \mathrm{h}$ to $10 \mathrm{~mm} / \mathrm{h}$ ) and C-reactive protein concentration was $28 \mathrm{mg} / \mathrm{L}$ (normal range $0 \mathrm{mg} / \mathrm{L}$ to $6 \mathrm{mg} / \mathrm{L}$ ). Serological testing for brucellosis, bartonellosis and Q fever was ordered at this time, and the patient was advised to return for follow-up in two weeks. However, his condition deteriorated suddenly, and he presented with cardiogenic shock with pulmonary edema, one week before his scheduled follow-up. He was taken to the operating room on an emergency basis and underwent a fourth prosthetic aortic valve replacement on July 14, 2004. Intraoperatively, dehiscence of his prosthetic valve was noted. A St Jude mitral prosthesis was inverted and inserted in the aortic valve annulus (33 MECJ-502, serial number 822892544, St Jude Medical Inc, USA).

Subsequently, the results of the patient's serology for $\mathrm{Q}$ fever were reported as strongly positive. Immunofluorescence assay technique was used to determine antibody against $\mathrm{C}$ burnetii. The phase II titre of anti-C burnetii immunoglobulin (Ig) G antibodies was higher than that of phase I (1:65,536 versus $1: 32,768)$ in his primary specimen, which suggested an acute infection (titres under 1:256 indicate past exposure and titres over 1:256 indicate recent or active infection). C burnetii DNA was also detected from his resected valve tissue by polymerase chain reaction (Figure 1), which further validated the presence of active infection. Histopathology of resected aortic valve tissue showed fibrous thickening of the valve cusp associated with degenerative changes, a focal inflammatory infiltrate of neutrophils, histiocytes and lymphocytes. Special stains for fungi and bacteria were negative. The postoperative course was complicated by a prolonged stay in the intensive care unit secondary to cardiac tamponade and intrapulmonary hematoma. Doxycycline $100 \mathrm{mg}$ twice daily and hydroxychloroquine $400 \mathrm{mg}$ once daily were administered postoperatively. After a prolonged hospital stay, the patient was discharged home with normal hemodynamics and aortic prosthetic valve function. Discharge medications included oral
TABLE 1

Follow-up results of indirect immunofluorescence assay immunoglobulin $\mathbf{G}$

\begin{tabular}{lrr}
\hline Date & Phase I & Phase II \\
\hline July 2004 & $1: 32,768$ & $1: 32,768$ \\
August 2004 & $1: 16,384$ & $1: 32,768$ \\
January 2005 & $1: 8192$ & $1: 16,384$ \\
April 2005 & $1: 16,384$ & $1: 32,768$ \\
October 2005 & $1: 32,768$ & $1: 65,536$ \\
January 2006 & $1: 32,768$ & $1: 131,072$ \\
April 2006 & $1: 16,384$ & $1: 65,536$ \\
\hline
\end{tabular}

ciprofloxacin $500 \mathrm{mg}$ and doxycycline $100 \mathrm{mg}$, both twice daily. Rifampin was not used because of the patient's requirement for warfarin treatment and the concern about drug interactions. Follow-up C burnetii serology in January 2005 revealed a transient decrease in titre with phase I IgG 1:8192 and phase II IgG $1: 16,384$. However, a rise in titre was noted with phase I IgG 1:16,384 and phase II IgG 1:32,768 in April 2005. Based on these results, the ciprofloxacin was replaced with hydroxychloroquine $400 \mathrm{mg}$ once daily. A further rise in titre was noted, with phase I IgG $1: 32,768$ and phase II $\operatorname{IgG} 1: 65,536$ in October 2005, and the hydroxychloroquine was changed to 600 mg daily. In January 2006, his titre was still increasing, with phase I $\operatorname{IgG} 1: 32,768$ and phase II $\operatorname{IgG} 1: 131,072$. His latest serology in April 2006 revealed a decline in his titre, with phase I IgG 1:16,384 and phase II IgG 1:65,536 (Table 1). He has since remained asymptomatic, with normal prosthetic valve hemodynamics.

\section{DISCUSSION}

We describe a case of recurrent, culture-negative endocarditis with multiple episodes of prosthetic aortic valve dysfunction secondary to unrecognized chronic $\mathrm{C}$ burnetii infection spanning a period of at least three years. The diagnosis of $Q$ fever infection was confirmed by high titre anti-C burnetii phase II antibodies, as well as by the detection of $\mathrm{C}$ burnetii DNA in resected valve tissue by polymerase chain reaction. The true prevalence of $Q$ fever may be underestimated because this disease can be asymptomatic in infected individuals (1). Q fever is found worldwide, and this zoonotic infection has many different reservoirs, including arthropods (mainly ticks), birds and mammals (2). The sources of human infection are usually cattle, sheep, goats and farm animals. There have been reports of transmission of disease through contact with other animals, such as dogs, cats, rabbits, pigeons and rats. C burnetii can be found in the urine, feces and milk of infected mammals (3). In British Columbia, data on $\mathrm{C}$ burnetii in animals are sparse: one of 10 mice (Peromyscus maniculatus) showed antibodies against C burnetii from a farm area where a goat was aborted due to C burnetii infection (M Morshed, personal communication). $Q$ fever can also develop in the absence of direct animal contact. Meiklejohn et al (4) described an outbreak of Q fever among personnel involved in perinatal research at the University of Colorado Health Sciences Center in Denver, Colorado (USA). Only 41 of the 137 seropositive individuals were caring for pregnant sheep. Q fever cases were not observed after the removal of sheep from the facility.

Endocarditis is the most common manifestation of chronic $Q$ fever. Older individuals and immunocompromised patients 
are at greater risk for developing chronic $Q$ fever (5). Pre-existing valvular heart disease and prosthetic valves are recognized risk factors for $Q$ fever endocarditis (6-8). Siegman-Igra et al (5) reviewed 408 cases of $Q$ fever endocarditis between 1949 and 1994. Underlying valvular heart disease was almost invariably present, and $38 \%$ of patients had prosthetic valves (5). Q fever endocarditis is rarely reported in Canada. Haldane et al (9) described five cases of $Q$ fever endocarditis in Nova Scotia between 1981 and 1982. Four patients had underlying valvular heart disease, including two patients who had prosthetic valves.

C burnetii is not a true rickettsia-like organism, but rather a gamma proteobacteria (order Legionellales), with its closest relationship among pathogenic bacteria being Legionella pneumophila. C burnetii is a pleomorphic Gram-negative intracellular coccobacillus with distinct characteristics that contribute to its pathogenicity. It infects and multiplies in macrophages and survives within phagolysosomes. The organism also undergoes sporulation in the environment, where it can withstand harsh conditions for extended periods of time (10). C burnetii and Bartonella species appear to be the most common etiological agents of culture-negative endocarditis caused by fastidious or difficult-to-grow organisms. Compared with culture-positive cases, the etiological diagnosis of culture-negative endocarditis is delayed, resulting in an increased risk of valve destruction, septic emboli and higher mortality (11)

Endocarditis is a particularly severe and often fatal form of chronic $Q$ fever infection. The mortality from $Q$ fever endocarditis was $24 \%$ in one case series (12). Compounding the diagnostic difficulties in $Q$ fever endocarditis is the nonspecific nature of the clinical symptoms with which patients present. Constitutional symptoms, congestive heart failure and valvular dysfunction may be the initial presenting symptoms (13). In a review of 19 cases of $Q$ fever endocarditis (8), only five patients had fever, while 10 patients presented with heart failure and valvular dysfunction. Houpikian et al (14) described the changing clinical presentation of 15 cases of $Q$ fever endocarditis between 1999 and 2000 compared with 15 cases reported in 1987. Significant decreases were found in the prevalence of heart failure, anemia, leukopenia and abnormal liver function test results in patients who had $Q$ fever endocarditis after 1997 (14). Because C burnetii is an intracellular pathogen, it does not grow in conventional blood cultures and requires special cell culture conditions (11). Vegetations are seen infrequently on echocardiography. Among the 19 cases of $Q$ fever endocarditis reviewed by Salamand et al (8), transthoracic and transesophageal echocardiography were considered positive for vegetations in only six cases.

In another review of 63 cases of apparently culture-negative endocarditis (15), organisms were identified among 31 cases using serology, microscopy, culture or polymerase chain reaction of resected valves. Diagnosis of $Q$ fever endocarditis can be confirmed readily by serology (16). There are several serological tests available for the diagnosis of $Q$ fever, including complement fixation, indirect immunofluorescence assay (IFA) and ELISA. Although a complement fixation titre of 1:200 has been considered to be diagnostic for $Q$ fever endocarditis (10), other more sensitive assays are available, such as IFA. Indirect immunofluorescence offers good sensitivity and specificity and it is considered the reference test of choice for the diagnosis of Coxiella endocarditis (17). In the revised Duke criteria of infective endocarditis, an IgG anti-phase I antibody IFA titre of over 1:800 is used for the diagnosis of $Q$ fever endocarditis (16). In contrast, Houpikian and Raoult (11), in their review of practice guidelines for the diagnosis of culture-negative infective endocarditis, suggested that a cut-off of over 1:1600 (phase I IgG IFA) be used for the diagnosis of $Q$ fever endocarditis. They cited that this titre provided a positive predictive value of $98 \%(11,18)$. Thus, there is a general consensus that IgG IFA phase I titres of at least 1:800 are highly indicative of $Q$ fever endocarditis. In addition to a role in diagnosis, phase II IFA titres are also useful in monitoring response to treatment of $Q$ fever (17).

When evaluating patients with unexplained prosthetic valve dysfunction - as the current case illustrates - it is of the utmost importance to obtain a detailed history of contact with animals. In addition, a high index of clinical suspicion for $Q$ fever endocarditis is required in the setting of culturenegative, prosthetic valve endocarditis. Issartel et al (19) reported a case of unexplained severe mitral regurgitation. The diagnosis of $Q$ fever was confirmed by $C$ burnetii serology, polymerase chain reaction, positive culture of valve tissue on human embryonic lung fibroblasts and immunohistochemistry (19). Noseda et al (20) reported a case of unexplained culturenegative endocarditis requiring mitral valve replacement, followed five years later by another episode of culture-negative endocarditis. In the second episode of endocarditis, $Q$ fever was considered and $\mathrm{C}$ burnetii antibody titre was high. Retrospective review of the resected valves from the first episode of endocarditis, using the Giemsa and Machiavello stains, revealed coccobacilli, consistent with C burnetii infection (20).

The optimal choice and duration of antibiotics for $Q$ fever endocarditis have not been established. Levy et al (21) evaluated different antibiotic regimens for the treatment of 32 cases of $Q$ fever endocarditis. The combination of doxycycline and quinolones appeared to be more effective than doxycycline alone in reducing mortality. On the basis of clinical, serological and valve tissue culture results, no treatment regimen was found to cure $Q$ fever endocarditis within two years, even with a combination of antibiotics. The investigators advised a minimum duration of treatment of three years, with therapy combining a quinolone with doxycycline (21). In addition, limited experience appeared to suggest that a combination of doxycycline plus hydroxychloroquine was superior to doxycycline alone in preventing the development of endocarditis in the management of acute $Q$ fever (6). In a meta-analysis of 408 cases of $Q$ fever endocarditis, Siegman-Igra et al (5) reported that the death rate was significantly lower among patients who received a tetracycline in combination with rifampin, ciprofloxacin or trimethoprim-sulfamethoxazole $(18 \%)$ compared with patients treated with a tetracycline alone (44\%). Despite prolonged and combined medical therapy, valve dysfunction may be a late sequelae necessitating valve replacement. In a series (8) evaluating 19 cases of Q fever endocarditis (including 10 with prosthetic valves), early valve replacement was carried out in 15 patients for hemodynamic instability, hemolytic anemia and perivalvular abscess. Three of the four patients who initially received medical therapy alone subsequently required surgery to correct due to failure of the bioprosthesis. Of the 16 patients for whom long-term follow-up was available, none showed signs of recurrence. All patients were treated with combined doxycycline/hydrochloroquine or a quinolone for a mean duration of 24 months. The mean follow-up time was 40 months (8). Whether aggressive and 
early surgical therapy for $Q$ fever prosthetic valve endocarditis may decrease the frequency of late relapse is not known and requires further study. Irrespective of therapeutic regimen and duration of treatment, patients with $Q$ fever endocarditis require prolonged follow-up because of the possibility of late relapse (13). In vitro studies have evaluated factors contributing to antibiotic failure and late relapse of $Q$ fever endocarditis. The acidic environment of the phagolysosome where $\mathrm{C}$ burnetii resides inhibits antibiotic activity. The addition of amantadine and chloroquine to $\mathrm{C}$ burnetii-infected cells decreases the acidity of the phagolysosome and enhances the activity of doxycycline. The combination of doxycycline with amantadine or chloroquine may be more effective in sterilizing $Q$ fever endocarditis compared with doxycycline monotherapy (22).

In conclusion, $\mathrm{Q}$ fever should be considered when evaluating patients with unexplained prosthetic valve dysfunction,

\section{REFERENCES}

1. Fournier PE, Marrie TJ, Raoult D. Diagnosis of Q fever. J Clin Microbiol 1998;36:1823-34.

2. Raoult D, Marrie T. Q fever. Clin Infect Dis 1995;20:489-95.

3. Stein A, Raoult D. Pigeon pneumonia in Provence: A bird-borne Q fever outbreak. Clin Infect Dis 1999;29:617-20.

4. Meiklejohn G, Reimer LG, Graves PS, Helmick C. Cryptic epidemic of Q fever in a medical school. J Infect Dis 1981;144:107-13.

5. Siegman-Igra Y, Kaufman O, Keysary A, Rzotkiewicz S, Shalit I. $Q$ fever endocarditis in Israel and a worldwide review. Scand J Infect Dis 1997;29:41-9.

6. Barrau K, Boulamery A, Imbert G, et al. Causative organisms of infective endocarditis according to host status. Clin Microbiol Infect 2004;10:302-8.

7. Fenollar F, Fournier PE, Carrieri MP, Habib G, Messana T, Raoult D. Risks factors and prevention of $\mathrm{Q}$ fever endocarditis. Clin Infect Dis 2001;33:312-6.

8. Salamand AC, Collart F, Caus T, et al. Q fever endocarditis: Over 14 years of surgical experience in a referral center for rickettsioses. J Heart Valve Dis 2002;11:84-90.

9. Haldane EV, Marrie TJ, Faulkner RS, et al. Endocarditis due to Q fever in Nova Scotia: Experience with five patients in 1981-1982. J Infect Dis 1983;148:978-85.

10. Marrie TJ, Raoult D. Coxiella burnetii (Q fever). In: Bennett JE, Dolin R, Mandell GL, eds. Principles and Practice of Infectious Diseases, 6th edition. Philadelphia: Churchill Livingstone, 2004.

11. Houpikian P, Raoult D. Diagnostic methods current best practices and guidelines for identification of difficult-to-culture pathogens in infective endocarditis. Infect Dis Clin North Am 2002;16:377-92. even in the absence of constitutional manifestations. A detailed history of exposure to animals, including pets, is crucial. Serology for C burnetii should be requested in all such cases. It would be of interest to have population-based data for C burnetii serology to evaluate titres in asymptomatic individuals with a history of exposure to pets. Further studies are required to evaluate the optimal antibiotic regimen and duration of therapy for $\mathrm{Q}$ fever endocarditis. The role of early surgery for prosthetic valve $Q$ fever endocarditis in preventing relapses needs to be determined.

ACKNOWLEDGEMENTS: None of the authors received financial support for the present report, and there are no conflicts of interest. Serological laboratory diagnostics were provided by Dr Steven Jones at the National Microbiology Laboratory in Winnipeg, Manitoba.

12. Brouqui $\mathrm{P}$, Dupont HT, Drancourt $\mathrm{M}$, et al. Chronic $\mathrm{Q}$ fever Ninety-two cases from France, including 27 cases without endocarditis. Arch Intern Med 1993;153:642-8.

13. Stein A, Raoult D. Q fever endocarditis. Eur Heart J 1995;16(Suppl B):19-23.

14. Houpikian P, Habib G, Mesana T, Raoult D. Changing clinical presentation of $Q$ fever endocarditis. Clin Infect Dis 2002;34:E28-31.

15. Lamas CC, Eykyn SJ. Blood culture negative endocarditis: Analysis of 63 cases presenting over 25 years. Heart 2003;89:258-62.

16. Choi E. Tularemia and Q fever. Med Clin North Am 2002;86:393-416.

17. Slaba K, Skultety L, Toman R. Efficiency of various serological techniques for diagnosing Coxiella burnetii infection. Acta Virol 2005;49:123-7

18. Dupont HT, Thirion X, Raoult D. Q fever serology: Cutoff determination for microimmunofluorescence. Clin Diagn Lab Immunol 1994;1:189-96.

19. Issartel B, Gauduchon V, Chalabreysse L, et al. Clinically and histologically silent $Q$ fever endocarditis accidentally diagnosed by PCR. Clin Microbiol Infect 2002;8:113-4.

20. Noseda A, Liesnard C, Goffin Y, Thys JP. Q fever endocarditis: Relapse five years after successful valve replacement for a first unrecognized episode. J Cardiovasc Surg (Torino) 1988;29:360-3.

21. Levy PY, Drancourt M, Etienne J, et al. Comparison of different antibiotic regimens for therapy of 32 cases of $Q$ fever endocarditis. Antimicrob Agents Chemother 1991;35:533-7.

22. Raoult D, Drancourt M, Vestris G. Bactericidal effect of doxycycline associated with lysosomotropic agents on Coxiella burnetii in P388D1 cells. Antimicrob Agents Chemother 1990;34:1512-4. 


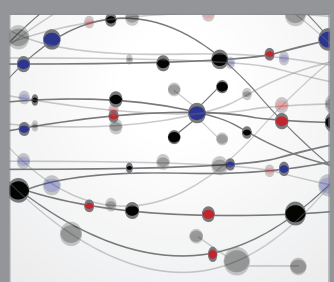

The Scientific World Journal
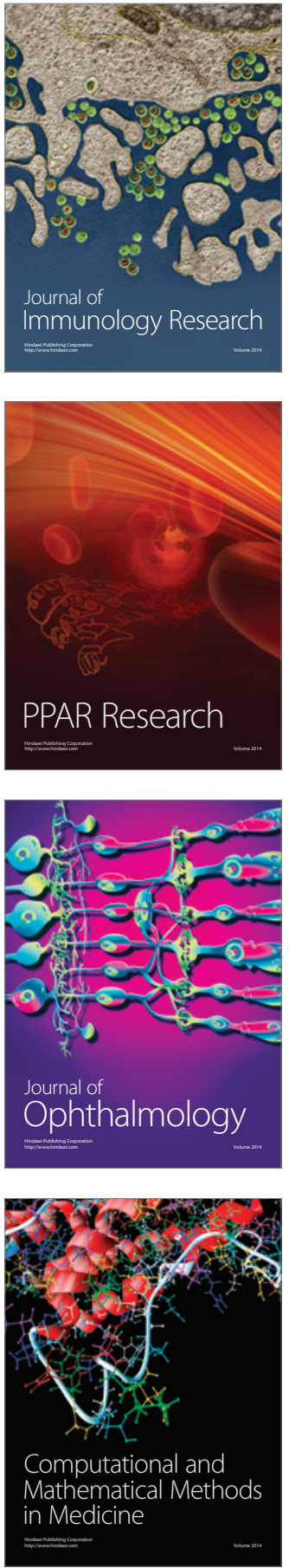

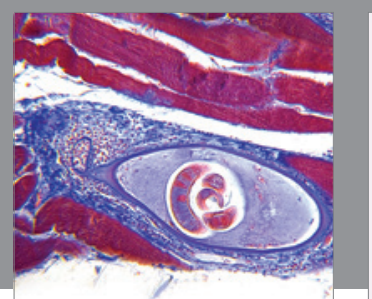

Gastroenterology Research and Practice

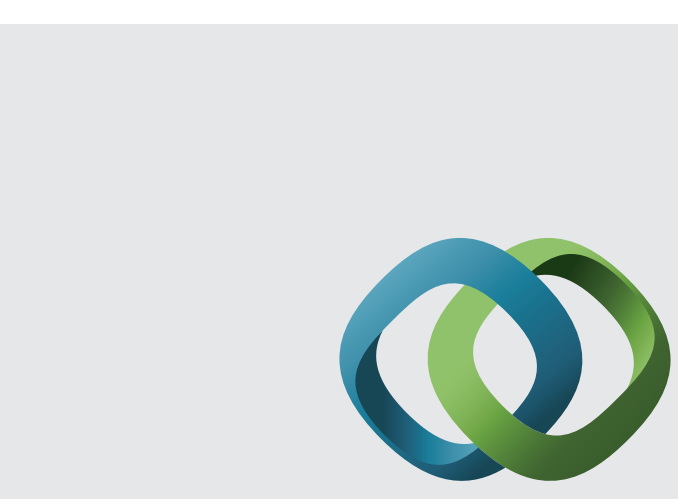

\section{Hindawi}

Submit your manuscripts at

http://www.hindawi.com
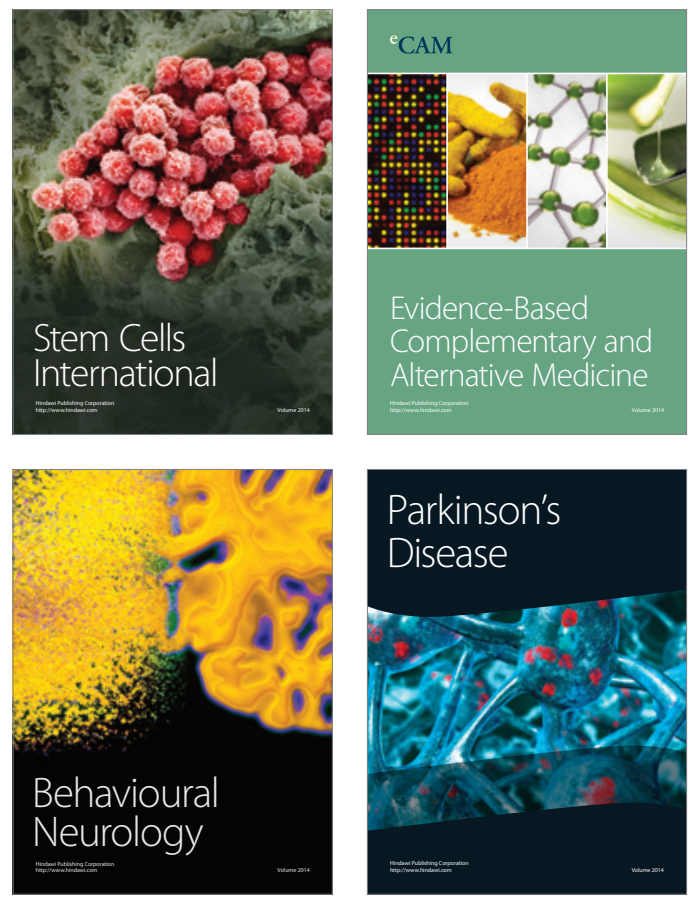
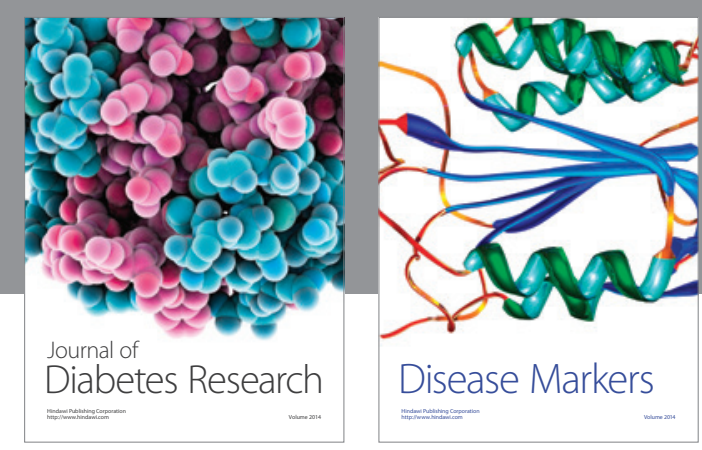

Disease Markers
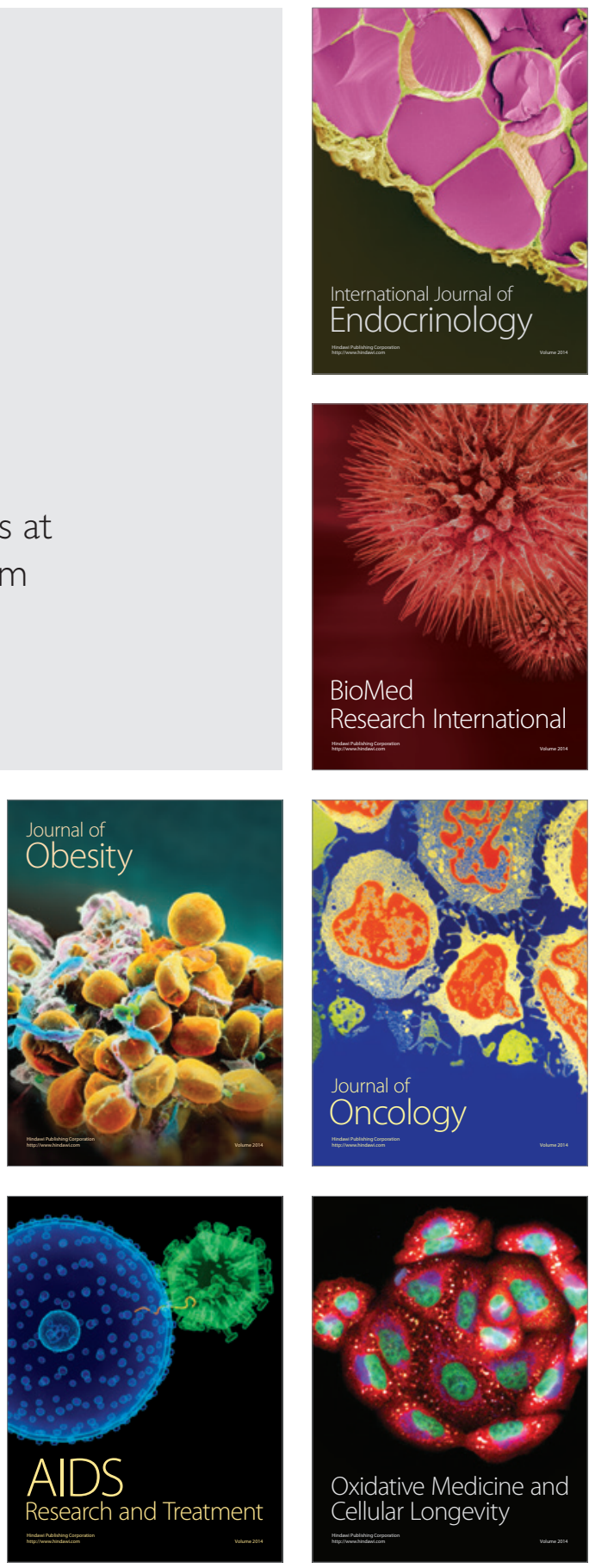